\title{
ANALISIS SISTEM PENGELOLAAN \\ SAMPAH PERKANTORAN KOTA PADANG MENGGUNAKAN METODE LIFE CYCLE ASSESSMENT
}

\section{ANALYSIS OF SOLID WASTE MANAGEMENT SYSTEM OF INSTITUTIONAL SOURCE OF PADANG CITY USING LIFE CYCLE ASSESSMENT METHOD}

\author{
Rizki Aziz, dan Febriardy \\ Jurusan Teknik Lingkungan Fakultas Teknik Universitas Andalas \\ Kampus Limau Manis Padang, \\ E-mail : rizkiaziz@ft.unand.ac.id
}

\begin{abstract}
ABSTRAK
Life Cycle Assessment (LCA) merupakan suatu metode yang digunakan untuk menilai dan mengevaluasi total dampak bagi lingkungan yang ditimbulkan oleh suatu produk, proses atau layanan. Aplikasi LCA sederhana dilakukan pada sistem pengelolaan sampah perkantoran Kota Padang yang memiliki dua jenis sistem pengelolaan, yaitu pengelolaan sampah sistem tercampur dan pengelolaan sampah sistem terpisah. Pendekatan yang digunakan adalah sistem pengelolaan sampah pada Balai Kota Padang dengan timbulan sampah sebesar 5,1194 $\mathrm{m}^{3} /$ minggu. Tahapan daur hidup pengelolaan sampah sistem tercampur meliputi tahap timbulan, tahap pewadahan, tahap pengumpulan, tahap pengangkutan ke Tempat Pembuangn Akhir (TPA), tahap pengolahan di TPA, tahap pengangkutan ke lapak dan tahap pengolahan di lapak (lapak besar dan bandar), sedangkan untuk sistem terpisah terdiri dari tahap timbulan, tahap pewadahan, tahap pengumpulan, tahap pengangkutan ke lapak, tahap pengolahan di lapak (lapak kecil, lapak besar, dan Bandar), tahap pengangkutan ke TPA, dan tahap pengolahan di TPA. Total buangan material sebesar 6,6320 $\mathrm{m}^{3} /$ minggu untuk sistem tercampur dan 4,1815 $\mathrm{m}^{3} /$ minggu untuk sistem terpisah, volume energi yang dibutuhkan sistem tercampur yaitu $0,0164 \mathrm{~m}^{3} /$ minggu dan 0,0102 $\mathrm{m}^{3} /$ minggu untuk sistem terpisah. Dampak lingkungan terbesar yang mungkin terjadi adalah potensi gangguan keseimbangan ekologi, yaitu sebesar 13,1519 satuan bobot untuk pengolahan di TPA sistem tercampur dan 7,7743 satuan bobot untuk pengolahan di TPA sistem terpisah. Berdasarkan hasil analisis yang diperoleh, untuk sampah dengan kuantitas yang sama, sistem terpisah lebih ramah lingkungan dibandingkan sistem tercampur.
\end{abstract}

Kata-kata kunci: LCA sederhana, sistem pengelolaan sampah perkantoran, sistem tercampur, sistem terpisah, dampak lingkungan

\begin{abstract}
Life Cycle Assessment (LCA)is a method to assess and to evaluate total environmental impact of a product, process or service. Simplified LCA has applied to solid waste management of institutional source of Padang City which applies two types of systems included Mixed Management System and Separated Management System. Study based on solid waste management of Major Office of Padang City which generated waste as $5.1194 \mathrm{~m}^{3}$ per week. Life cycle of mixed management system consist of generation, storage, collection, transportation to landfill, treatment on landfill, transportation to informal recycler, and treatment of informal recycler. Separated management system consist of generation, storage, collection, transportation to informal recycler, treatment on informal recycler, transportation to landfill, and treatment on landfill. Total material generated was $6.6320 \mathrm{~m}^{3} /$ week on mixed system and $4.1815 \mathrm{~m}^{3} /$ week on separated system. Energy needed for mixed system was 0.0164 $\mathrm{m}^{3} /$ week and $0.0102 \mathrm{~m}^{3} /$ week on separated system. The highest environmental impact for both systems were on ecosystem quality damage for treatment on landfill phase as 13.1519 weighting unit of mixed system and 7.7743 weighting unit for treatment on landfill for separated system. Comparative analysis of both systems on equal quantity of waste reveals that separated system is more environmentally friendly than mixed system.
\end{abstract}

Keywords: Simplified LCA, solid waste management system of institutional source, mixed system, separated system, environmental impact 



\section{PENDAHULUAN}

Secara umum sistem pengelolaan sampah yang sedang dilaksanakan perkantoran di Kota Padang saat ini adalah pengelolaan sampah yang dimulai dari sumber, pewadahan, pengumpulan, pengolahan, dan transportasi sampah hingga ke Tempat Pembuangan Akhir (TPA). Ada kantor yang langsung membuang sampah yang dihasilkannya untuk dibawa ke TPA. Ada juga kantor yang melakukan pemilahan terhadap sampah yang dihasilkannya untuk didaur ulang, seperti sampah kertas, plastik, dan lain sebagainya.

Adanya perbedaan pelaksanaan sistem pengelolaan sampah akan menimbulkan dampak lingkungan yang berbeda. Penilaian terhadap sistem pengelolaan sampah perkantoran Kota Padang perlu dilakukan untuk mencegah terjadinya dampak terhadap lingkungan dan kesehatan manusia, yang dimulai dari awal (sumber) sampai akhir proses pengelolaan (TPA). Life Cycle Assessment (LCA) merupakan suatu metode yang digunakan untuk menilai dan mengevaluasi total dampak bagi lingkungan yang ditimbulkan oleh suatu produk, proses atau layanan, termasuk pelaksanaan sistem pengelolaan sampah perkantoran kota.

Tujuan penelitian ini adalah:

1. Mengetahui daur hidup dua sistem pengelolaan sampah intitusi Kota Padang;

2. Menganalisis potensi dampak lingkungan pada pelaksanaan dua sistem pengelolaan sampah institusi Kota Padang;

3. Menginterpretasikan potensi dampak lingkungan untuk memprioritaskan alternatif solusi dalam meminimalkan dampak.

\section{METODOLOGI}

Penelitian yang dilakukan adalah penelitian terapan LCA sederhana. Pada penelitian ini yang diukur adalah data kuantitatif sampah yang dihasilkan serta energi yang digunakan dan dibuang ke lingkungan pada setiap daur hidup sistem pengelolaan sampah institusi yang menggunakan sistem pengelolaan sampah tercampur serta institusi yang menggunakan sistem pengelolaan sampah terpisah, yaitu pemilahan dan pengolahan sampah di sumber untuk didaur ulang, sampai pada sistem pembuangan akhirnya.

\section{Pengumpulan Data}

Terdiri atas data skunder dan primer. Data sekunder berupa gambaran umum Kota Padang, kondisi eksisting pengelolaan sampah Kota Padang terkait dengan aspek legal, aspek kelembagaan, aspek teknis operasinal, aspek pembiayaan, dan aspek peran serta masyarakat. Aspek teknis operasionalnya terdiri dari aspek timbulan, pewadahan, pengumpulan, pengolahan (pengomposan, daur ulang, insenerasi), pengangkutan dan tempat pembuangan akhir sampah.

Data Primer diperoleh dengan melakukan survei dan pengambilan langsung ke lokasi studi yaitu meliputi pengukuran volume timbulan sampah kantor di Kota Padang yang memiliki perbedaan sistem pengelolaan sampah; menghitung berat masing-masing komposisi sampah kantor yang diteliti; melakukan pengamatan terhadap jenis-jenis pewadahan yang digunakan institusi dalam pengelolaan sampah; melakukan pengamatan terhadap sampah dari lokasi penelitian pada pengolahan yang dilakukan di Tempat Pembuangan Akhir (TPA) untuk melihat perlakuan yang diberikan terhadap sampah; wawancara dan penyebaran kuesioner.

\section{Prosedur Penelitian}

\section{Survei pendahuluan}

Tahap ini mencakup survei awal ke lokasi penelitian dan studi literatur mengenai kajian daur hidup serta penelitian-penelitian yang berkaitan dengan persampahan.

\section{Tahap persiapan}

Tahap persiapan ini terdiri dari penentuan sampel dan persiapan sebelum sampling dilakukan.

\section{Penentuan dan perlakuan sampel}

Perlakuan yang pertama adalah untuk sistem pengelolaan sampah tercampur. Pengukuran berat dan volume sampah dilakukan dengan memisahkan sampah berdasarkan jenisnya. Perlakuan yang ke dua adalah untuk sistem pengelolaan sampah terpisah. Hal ini dilakukan dengan cara melakukan 
pemisahan sampah-sampah pada Balai Kota Padang yang biasa didaur ulang oleh institusi-institusi yang ada di Kota Padang seperti sampah kertas dan plastik, serta dilakukan pengukuran volume dan beratnya.

\section{Analisis Daur Hidup}

Adapun langkah dan tahapan implementasi analisis daur hidup dalam sistem pengelolaan sampah institusi Kota Padang adalah pendefinisian tujuan dan batasan sistem, pengumpulan data untuk analisis inventarisasi, penilaian dampak daur hidup, dan interpretasi daur hidup

\section{HASIL DAN PEMBAHASAN}

\section{Penentuan Tujuan dan Batasan LCA}

Tujuan LCA adalah menentukan, menganalisis dan membandingkan dampak lingkungan utama yang timbul pada setiap tahapan daur hidup dua sistem pengelolaan sampah institusi, yaitu pengelolaan sampah sistem tercampur (PSSC) dan pengelolaan sampah sistem terpisah (PSSP).

Batasan kajian yang ditetapkan dalam penelitian ini adalah:

1. Kajian dilakukan terhadap jumlah timbulan, energi, dan emisi yang dihasilkan dalam tahapan daur hidup dua sistem pengelolaan sampah kota yang meliputi jumlah timbulan, pewadahan, pengumpulan, pengolahan dan pengangkutan sampah;

2. Dampak lingkungan yang ditimbulkan oleh kegiatan pemeliharaan peralatan yang digunakan dalam proses pengangkutan sampah dan penggilingan sampah untuk daur ulang tidak dikaji;

3. Kajian terhadap sistem pengolahan sampah yang bisa didaur ulang hanya sampai pada bandar.

\section{Pengolahan Data di Lapangan}

Data lapangan diperoleh dari dua sumber utama, yaitu pengukuran dan penyebaran kuisioner. Pengukuran dilakukan terhadap timbulan dan komposisi sampah, sedangkan penyebaran kuisioner dilakukan untuk mendapatkan data perilaku karyawan/pegawai terhadap sampah yang dihasilkan dan jumlah energi (bahan bakar) yang dibutuhkan truk pengangkutan dan mesin pemotong plastik proses daur ulang sampah, didapatkan melalui wawancara dengan sopir dan operator alat.

\section{Sistem Pengelolaan Sampah Institusi}

Sistem pengelolaan sampah di institusi yang dikaji memiliki dua model yaitu pengelolaan sampah tercampur (PSSC) dan sampah terpisah (PSSP). Tahapan daur hidup pengelolaan sampah sistem tercampur meliputi tahap: (a) timbulan, (b) pewadahan, (c) pengumpulan, (d) pengangkutan ke Tempat Pembuangan Akhir (TPA), (e) pengolahan di TPA, (f) pengangkutan ke lapak dan (g) pengolahan di lapak (lapak besar dan bandar). Adapun sistem terpisah terdiri dari atas tahap: (a) timbulan, (b) pewadahan, (c) pengumpulan, (d) pengangkutan ke lapak, (e) pengolahan di lapak (lapak kecil, lapak besar, dan Bandar), (f) pengangkutan ke TPA, dan (g) pengolahan di TPA.

\section{Timbulan dan Komposisi Sampah Balai Kota Padang}

Pengukuran berat dan volume sampah dilakukan dengan melakukan penimbangan terhadap semua sampah yang dihasilkan Balai Kota Padang selama delapan hari berturut-turut menggunakan timbangan. Timbulan pada hari kedelapan digunakan untuk menghitung faktor koreksi timbulan.

Data dan hasil pengukuran timbulan balai kota padang selama satu minggu dapat dilihat pada tabel 1 berikut.

Tabel 1. Komposisi Sampah PSSC

\begin{tabular}{llcccc}
\hline No & Jenis & $\begin{array}{c}\text { Berat } \\
(\mathbf{k g})\end{array}$ & $\begin{array}{c}\text { Berat } \\
(\mathbf{\%})\end{array}$ & $\begin{array}{c}\text { Volume } \\
(\mathbf{m 3})\end{array}$ & $\begin{array}{c}\text { Volume } \\
(\boldsymbol{\%})\end{array}$ \\
\hline 1 & S. makanan & 311,59 & 50,24 & 1,383 & 27,05 \\
2 & S. halaman & 41,81 & 6,74 & 0,483 & 9,45 \\
3 & Kertas & 139,57 & 22,50 & 1,902 & 37,18 \\
4 & Kain/tekstil & 2,19 & 0,35 & 0,003 & 0,05 \\
5 & Karet & 1,03 & 0,17 & 0,002 & 0,04 \\
6 & Plastik & 96,93 & 15,63 & 1,331 & 26,03 \\
7 & Logam & 7,19 & 1,16 & 0,006 & 0,12 \\
8 & Kaca & 19,83 & 3,20 & 0,005 & 0,09 \\
9 & Keramik & 0,08 & 0,01 & 0,0003 & 0,01 \\
\hline
\end{tabular}

Pengukuran sampah di atas juga dilakukan setelah sampah tersebut berada di TPA, yaitu terhadap sampah-sampah yang dikumpulkan oleh pemulung untuk dijual kembali sebagai bahan daur ulang. Adapun jenis sampah yang diambil pemulung adalah 
sampah kertas, plastik, dan logam. Data dan hasil pengukurannya dapat dilihat pada tabel 2.

Tabel 2. Komposisi Sampah dari TPA ke Lapak Besar PSSC

\begin{tabular}{|c|c|c|c|c|c|c|}
\hline No & Jenis & Komposisi & $\begin{array}{c}\text { Berat } \\
\text { (kg) }\end{array}$ & $\begin{array}{c}\text { Berat } \\
(\%)\end{array}$ & $\begin{array}{c}\text { Volume } \\
\text { (m3) }\end{array}$ & $\begin{array}{c}\text { Volume } \\
(\%)\end{array}$ \\
\hline \multirow[t]{3}{*}{1} & Kertas & K. Arsip & 8,48 & 22,59 & 0,08 & 18,55 \\
\hline & & Karton & 10,23 & 27,25 & 0,12 & 28,76 \\
\hline & & Kardus & 18,83 & 50,16 & 0,22 & 52,69 \\
\hline \multicolumn{2}{|c|}{ Total } & & 37,54 & 100 & 0,42 & 100 \\
\hline \multirow[t]{3}{*}{2} & Plastik & PP & 9,99 & 43,51 & 0,14 & 42,85 \\
\hline & & PET & 11,08 & 48,29 & 0,15 & 47,28 \\
\hline & & HDPE & 1,88 & 8,20 & 0,03 & 9,87 \\
\hline \multicolumn{2}{|c|}{ Total } & & 22,95 & 100 & 0,32 & 100 \\
\hline 3 & Logam & Aluminium & 1,25 & 100 & 0,001 & 100 \\
\hline \multicolumn{3}{|c|}{ Total } & 1,25 & 100 & 0,001 & 100 \\
\hline \multicolumn{3}{|c|}{ Total } & 61,74 & - & 0,74 & - \\
\hline
\end{tabular}

Komposisi sampah PSSC sama dengan komposisi sampah PSSP. Pada PSSP, kertas dan plastik dipisahkan berdasarkan jenisnya dan dihitung sampah yang memiliki potensi daur ulang dan non daur ulang. Komposisi sampah kertas dan plastik pada PSSP dapat dilihat pada Tabel 3, Tabel 4, dan Tabel 5.

Tabel 3. Komposisi Sampah Kertas dan Plastik pada PSSP

\begin{tabular}{lllllll}
\hline No & Jenis & \multicolumn{2}{l}{ Karakteristik } & Berat & \multicolumn{3}{l}{ Volume } \\
\cline { 3 - 7 } & & & $(\mathbf{k g})$ & $(\mathbf{\%})$ & $\left(\mathbf{m}^{\mathbf{3}}\right)$ & $\mathbf{( \% )}$ \\
\hline 1 & Kertas & daur ulang & 111,82 & 80 & 15,78 & 98 \\
& $\begin{array}{l}\text { non daur } \\
\text { ulang }\end{array}$ & 27,84 & 20 & 0,32 & 2 \\
& & & & & \\
\hline & Total & & 139,66 & 100 & 16,10 & 100 \\
\hline 2 & Plastik & daur ulang & 73,95 & 76 & 0,95 & 71 \\
& & non daur & 23,21 & 24 & 0,39 & 29 \\
& ulang & & & & \\
\hline & Total & & 97,16 & 100 & 1,34 & 100 \\
\hline & & & $\mathbf{2 3 6 , 8 2 1}$ & - & $\mathbf{1 7 , 4 4}$ & - \\
\hline
\end{tabular}

Tabel 4. Komposisi Sampah Kertas PSSP

\begin{tabular}{|c|c|c|c|c|c|}
\hline No & Jenis & $\begin{array}{c}\text { Berat } \\
\text { (kg) }\end{array}$ & $\begin{array}{c}\text { Berat } \\
(\%)\end{array}$ & $\begin{array}{c}\text { Volume } \\
\text { (m3) }\end{array}$ & $\begin{array}{c}\text { Volume } \\
(\%)\end{array}$ \\
\hline \multicolumn{6}{|c|}{ Dapat di daur ulang } \\
\hline 1 & K. arsip & 58,31 & 42 & 0,62 & 32 \\
\hline 2 & Karton & 29,31 & 21 & 0,45 & 24 \\
\hline 3 & Kardus & 14,41 & 10 & 0,37 & 19 \\
\hline 4 & K. koran & 5,68 & 4 & 0,09 & 5 \\
\hline \multirow[t]{2}{*}{5} & K. campuran & 4,11 & 3 & 0,05 & 3 \\
\hline & Total & 111,82 & 80 & 1,58 & 83 \\
\hline \multicolumn{6}{|c|}{ Tidak dapat di daur ulang } \\
\hline 1 & Bungkus nasi & 10,91 & 8 & 0,17 & 9 \\
\hline 2 & Art paper & 7,42 & 5 & 0,07 & 4 \\
\hline 3 & Tisu & 3,76 & 3 & 0,03 & 1 \\
\hline 4 & K. karbon & 0,82 & 1 & 0,01 & 1 \\
\hline \multirow[t]{2}{*}{5} & Lain-lain & 4,93 & 3 & 0,05 & 2 \\
\hline & Total & 27,84 & 20 & 0,33 & 17 \\
\hline
\end{tabular}

Tabel 5. Komposisi Sampah Plastik PPSP

\begin{tabular}{llcccc}
\hline No & Jenis & $\begin{array}{c}\text { Berat } \\
(\mathbf{k g})\end{array}$ & $\begin{array}{c}\text { Berat } \\
(\boldsymbol{\%})\end{array}$ & $\begin{array}{c}\text { Volume } \\
(\mathbf{m 3})\end{array}$ & $\begin{array}{c}\text { Volume } \\
(\mathbf{\%})\end{array}$ \\
\hline \multicolumn{2}{c}{ Dapat di daur ulang } & & & & \\
\hline 1 & PP & 41,50 & 43 & 0,54 & 41 \\
2 & PET & 23,41 & 24 & 0,29 & 22 \\
3 & HDPE & 6,76 & 7 & 0,09 & 6 \\
4 & PVC & 2,28 & 2 & 0,03 & 2 \\
\hline \multicolumn{7}{l}{ Total } & 73,95 & 76 & 0,95 & 71 \\
\hline \multicolumn{2}{l}{ Tidak dapat di daur ulang } & & & \\
\hline 1 & LDPE & 18,31 & 19 & 0,30 & 22 \\
\hline & PS & 4,91 & 5 & 0,09 & 7 \\
\hline
\end{tabular}

Pada proses awal PSSP melibatkan bahan penunjang dalam daur hidupnya, seperti karung dan tali rafia. Pada PSSC tidak terdapat bahan penunjang yang terlibat pada proses awal daur hidupnya. Pada PSSC, setelah sampah disortir pemulung di TPA, pemulung menggunakan bahan penunjang seperti tali rafia dan karung.

Hasil pengukuran bahan penunjang sampah dari TPA ke lapak pada PSSC dapat dilihat pada Tabel 6. Hasil pengukuran bahan penunjang PSSP dapat dilihat pada Tabel 7.

Tabel 6. Bahan Penunjang pada PSSC

\begin{tabular}{clll}
\hline No & \multicolumn{1}{c}{ Sampah } & Bahan & $\begin{array}{c}\text { Volume } \\
(\mathbf{m 3})\end{array}$ \\
\hline 1 & Kertas & Tali rafia & 0,048 \\
2 & Plastik dan logam & Karung & 0,077 \\
& & Tali rafia & 0,025 \\
\hline
\end{tabular}

Tabel 7. Bahan Penunjang di Sumber PSSP

\begin{tabular}{cllc}
\hline No & \multicolumn{1}{c}{ Sampah } & Bahan & $\begin{array}{c}\text { Volume } \\
(\mathbf{m} 3)\end{array}$ \\
\hline 1 & Kertas & Tali rafia & 0,150 \\
2 & Plastik dan logam & Karung & 0,461 \\
& & Tali rafia & 0,080 \\
\hline
\end{tabular}

\section{Analisis Inventarisasi}

Analisis inventarisasi dilakukan dengan menampilkan seluruh input dan output setiap tahapan daur hidup PSSC dan PSSP. Rekapitulasi neraca massa dan input energi untuk PSSC dan PSSP dapat dilihat pada tabel 8 sampai tabel 11.

\section{Analisis Dampak}

\section{Klasifikasi}

Klasifikasi dampak dilakukan berdasarkan kategori dampak, yaitu:

1. Kesetimbangan ekologi (ecological health); 
2. Kesehatan manusia (human health);

3. Penipisan sumber daya (resources depletion).

Tabel 8. Rekapitulasi Neraca Massa PSSC

\begin{tabular}{|c|c|c|c|c|}
\hline \multirow[t]{2}{*}{ No } & \multirow[t]{2}{*}{ Jenis } & \multirow{2}{*}{$\begin{array}{c}\text { Input } \\
\left(\mathbf{m}^{\mathbf{3}}\right)\end{array}$} & \multicolumn{2}{|c|}{ Output $\left(\mathrm{m}^{3}\right)$} \\
\hline & & & Material & Limbah \\
\hline 1 & S. makanan & 13,882 & 0,0000 & 13,882 \\
\hline 2 & S. halaman & 0,483 & 0,0000 & 0,483 \\
\hline 3 & Kertas & 19,017 & 0,4150 & 14,867 \\
\hline 4 & Kain/tekstil & 0,0026 & 0,0000 & 0,0026 \\
\hline 5 & Karet & 0,0019 & 0,0000 & 0,0019 \\
\hline 6 & Plastik & 13,311 & 0,2964 & 10,37 \\
\hline 7 & Logam & 0,0059 & 0,0010 & 0,0049 \\
\hline 8 & Kaca & 0,0046 & 0,0000 & 0,0046 \\
\hline 9 & Keramik & 0,0003 & 0,0000 & 0,0003 \\
\hline 10 & Karung & 0,0768 & 0,0768 & 0,0000 \\
\hline 11 & Tali rafia & 0,0730 & 0,0480 & 0,025 \\
\hline 12 & Air & 2,2000 & 0,0000 & 2,2000 \\
\hline
\end{tabular}

Tabel 9. Rekapitulasi Neraca MassaPSSP

\begin{tabular}{clccc}
\hline No & \multicolumn{1}{c}{ Jenis } & Input & \multicolumn{2}{c}{ Output $\left.\mathbf{( m}^{\mathbf{3}}\right)$} \\
\cline { 4 - 5 } & & $\left.\mathbf{( m}^{\mathbf{3}}\right)$ & Material & Limbah \\
\hline 1 & S. makanan & 13,882 & 0,0000 & 13,882 \\
2 & S. halaman & 0,483 & 0,0000 & 0,483 \\
3 & Kertas & 19,017 & 0,4150 & 14,867 \\
4 & Kain/tekstil & 0,0026 & 0,0000 & 0,0026 \\
5 & Karet & 0,0019 & 0,0000 & 0,0019 \\
6 & Plastik & 13,311 & 0,2964 & 10,37 \\
7 & Logam & 0,0059 & 0,0010 & 0,0049 \\
8 & Kaca & 0,0046 & 0,0000 & 0,0046 \\
9 & Keramik & 0,0003 & 0,0000 & 0,0003 \\
10 & Karung & 0,4610 & 0,4610 & 0,0000 \\
11 & Tali rafia & 0,2300 & 0,0800 & 0,1500 \\
12 & Air & 1,5000 & 0,0000 & 1,5000 \\
\hline
\end{tabular}

Tabel 10. Kebutuhan Energi PSSC

\begin{tabular}{lll}
\hline No & Kebutuhan BBM & Energi $\left(\mathbf{m}^{\mathbf{3}}\right)$ \\
\hline 1 & Transportasi dari sumber ke & 0,01 \\
& TPA & \\
2 & Transportasi dari lapak besar & $4,7 \times 10^{-5}$ \\
& ke bandar & \\
3 & Buldozer & 0,0056 \\
4 & Mesin potong plastik & $7,1 \times 10^{-4}$ \\
\hline Total & & 0,0163 \\
\hline
\end{tabular}

Tabel 11. Kebutuhan Energi PSSP

\begin{tabular}{lll}
\hline No & Kebutuhan BBM & Energi $\left(\mathbf{m}^{3}\right)$ \\
\hline 1 & $\begin{array}{l}\text { Trasnsportasi sampah non daur } \\
\text { ulang ke TPA }\end{array}$ & $5,07 \times 10$ \\
2 & $\begin{array}{l}\text { Transportasi s. kertas dari } \\
\text { sumber ke lapak besar }\end{array}$ & $5,1 \times 10^{-4}$ \\
3 & $\begin{array}{l}\text { Trasnportasi s. plastik dari } \\
\text { sumber ke lapak kecil }\end{array}$ & $1,9 \times 10^{-4}$ \\
4 & $\begin{array}{l}\text { Transportasi s. plastik dari } \\
\text { lapak kecil ke lapak besar }\end{array}$ & $4,4 \times 10^{-4}$ \\
5 & $\begin{array}{l}\text { Transportasi s. plastik dari } \\
\text { lapak besar ke bandar } \\
6\end{array}$ & $\begin{array}{l}\text { Transportasi plastik dari bandar } \\
\text { ke industri daur ulang }\end{array}$ \\
7 & $\begin{array}{l}\text { Buldozer } \\
\text { Mesin potong plastik }\end{array}$ & $1,43 \times 10^{-4}$ \\
\hline Total & & 0,0033 \\
\hline
\end{tabular}

Berdasarkan proses kegiatan yang telah diketahui, kandungan bahan dan kemungkinan dampak umum dapat dilihat pada tabel dibawah ini

Tabel 12. Potensi Dampak Umum

\begin{tabular}{llll}
\hline No & \multicolumn{1}{c}{ Bahan } & $\begin{array}{c}\text { Dampak } \\
(*)\end{array}$ & \multicolumn{1}{c}{$\begin{array}{c}\text { Tahap Daur } \\
\text { Hidup }\end{array}$} \\
\hline 1 & S. makanan & 2,3 & Tahap timbulan, \\
2 & S. kertas & $1,2,3$ & pewadahan, \\
3 & S. kain/tekstil & $1,2,3$ & pengumpulan, \\
4 & S. karet & 1,3 & pengolahan, dan \\
5 & S. plastik & $1,2,3$ & pengangkutan \\
6 & S. logam & 1,3 & sampah \\
7 & S. kaca & 1,3 & \\
8 & S. keramik & 1,3 & \\
9 & Tali rafia & $1,2,3$ & Tahap pengolahan \\
\hline 10 & Bahan bakar & $1,2,3$ & dan pengangkutan \\
\multicolumn{4}{c}{ sampah } \\
\hline Keterangan $\left.{ }^{*}\right)$ : 1. Penyusutan SDA 2. Gangguan kesehatan manusia \\
3. Gangguan keseimbangan ekologi
\end{tabular}

\section{Karakterisasi}

Karakterisasi dilakukan dengan menggunakan:

1. Urutan masalah lingkungan utama menurut US EPA yang dapat disimpulkan sebagai berikut:

- Bahan bakar bensin dan solar, sampah kertas, dan plastik berpotensi menimbulkan dampak utama lingkungan prioritas tinggi;

- Sampah makanan dan halaman, tekstil, logam, berpotensi menimbulkan dampak sedang

2. Berdasarkan kajian mengenai hubungan stressor dengan dampak yang ditimbulkan; bahan bakar, sampah kertas, plastik, sampah makanan dan halaman berpotensi menimbulkan gangguaan keseimbangan ekologi dan kesehatan manusia.

\section{Pembobotan}

Penentuan dampak lingkungan utama dari keseluruhan dampak yang ditimbulkan oleh sistem pengelolaan sampah balai kota melalui pembobotan sederhana yang menggunakan modifikasi matriks analisis dampak.

Pembobotan dilakukan berdasarkan pertimbangan besar kecilnya dampak yang ditimbulkan dari stressor yang ada. Pembobotan dampak lingkungan pada daur 
hidup sistem pengelolaan sampah dapat dilihat pada Tabel 13 dan 14 .

Pembobotan ini digunakan untuk melihat besarnya pembebanan lingkungan oleh komponen-komponen daur hidup sistem pengelolaan sampah yang berpengaruh besar terhadap penyusutan sumber daya alam (PSDA), gangguan kesehatan manusia (GKM) dan gangguan kesimbangan ekologi (GKE).

Tabel 13. Pembobotan Dengan Komposisi Matriks Analisis Dampak dan Matriks Paparan Primer (Lokal)

\begin{tabular}{|l|c|c|c|c|}
\hline Kom pon en & PS DA & GKM & GKE & Total \\
\hline S. mak anan dan halaman & 0 & 2 & 3 & 5 \\
\hline S. kertas & 2 & 3 & 3 & 8 \\
\hline S. kain/tekstil & 1 & 2 & 2 & 5 \\
\hline S. karet & 1 & 2 & 2 & 5 \\
\hline S.plastik & 2 & 3 & 3 & 8 \\
\hline S. logam & 1 & 2 & 2 & 5 \\
\hline S.kaca & 1 & 1 & 2 & 4 \\
\hline S.keramik & 1 & 1 & 2 & 4 \\
\hline Tali rafia & 1 & 2 & 2 & 5 \\
\hline Air & 0 & 0 & 0 & 0 \\
\hline BBM & 3 & 3 & 3 & 9 \\
\hline Total & $\mathbf{1 3}$ & $\mathbf{2 1}$ & $\mathbf{2 4}$ & $\mathbf{5 8}$ \\
\hline
\end{tabular}

Tabel 14. Pembobotan Dengan Komposisi Matriks Analisis Dampak dan Matriks Paparan Primer (Global)

\begin{tabular}{|l|c|c|c|c|}
\hline \multicolumn{1}{|c|}{ Dampak } & PSDA & GKM & GKE & Total \\
\hline Komponen & & & & \\
\hline S. makanan dan halaman & 0 & 2 & 2 & 4 \\
\hline S. kertas & 2 & 2 & 2 & 6 \\
\hline S. kain/tekstil & 0 & 0 & 0 & 0 \\
\hline S. karet & 2 & 2 & 2 & 6 \\
\hline S.p lastik & 0 & 0 & 0 & 0 \\
\hline S. logam & 0 & 0 & 0 & 0 \\
\hline S. kaca & 0 & 0 & 0 & 0 \\
\hline S. keramik & 0 & 0 & 0 & 0 \\
\hline Tali rafia & 0 & 0 & 0 & 0 \\
\hline A ir & 0 & 0 & 0 & 0 \\
\hline BBM & 2 & 2 & 2 & 6 \\
\hline Total & $\mathbf{6}$ & $\mathbf{8}$ & $\mathbf{8}$ & $\mathbf{2 2}$ \\
\hline
\end{tabular}

Pembebanan lingkungan dilihat dengan mengalikan besarnya buangan tiap komponen dengan pembobotan tingkat lokal. Adapun diagram pembebanan lingkungan sistem pengelolaan sampah institusi dapat dilihat pada Gambar 1 dan Gambar 2.

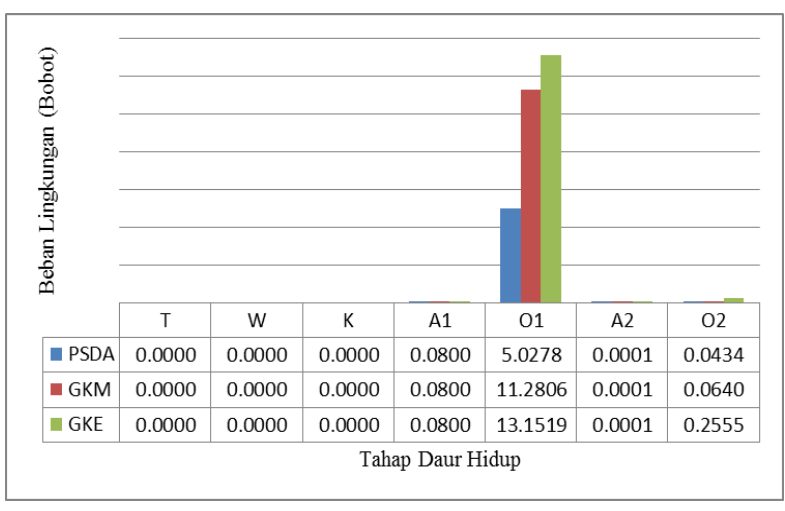

Keterangan: T: timbulan, W: pewadahan, $\mathrm{K}$ : pengumpulan, A1: pengangkutan ke TPA, O1: pengolahan di TPA, A2: pengangkutan ke lapak, O2: pengolahan di lapak

\section{Gambar 1. Beban Lingkungan PSSC}

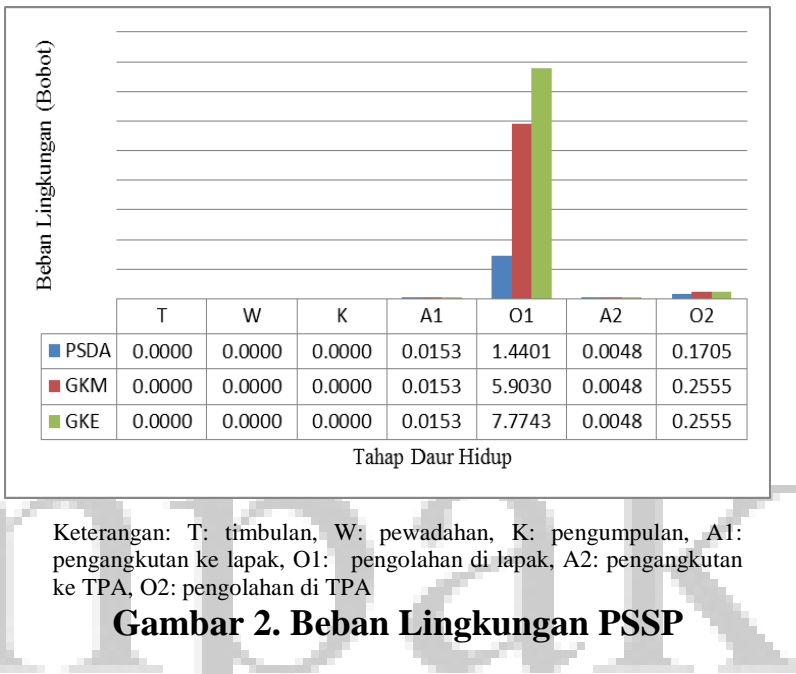

Perbandingan dilakukan pada seluruh tahapan sistem pengelolaan sampah institusi, yaitu tahap timbulan, pewadahan, pengumpulan, transportasi, dan pengolahan sampah baik sistem tercampur maupun sistem terpisah.

Berdasarkan gambar diatas, dapat dilihat bahwa:

- Pada tahap timbulan, pewadahan, dan pengumpulan sampah sistem pengelolaan sampah institusi baik sistem tercampur maupun sistem terpisah tidak ada beban lingkungan yang ditimbulkan;

- Beban lingkungan yang ditimbulkan terdapat pada tahap pengolahan dan pengangkutan sampah baik sistem tercampur maupun terpisah;

- Pada tahap pengangkutan PSSC maupun PPSP hanya emisi yang berasal dari pembakaran bahan bakar minyak 
kendaraan pengangkut sampah yang menimbulkan beban lingkungan;

- Secara keseluruhan beban lingkungan pengelolaan sampah institusi PSSC lebih besar dari pada PSSP.

\section{Interpretasi Daur Hidup}

\section{Interpretasi Daur Hidup Sistem Pengelolaan Sampah Sistem Tercampur}

Tabel pembobotan lingkungan menunjukkan bahwa:

1. Beban lingkungan terbesar adalah tahap pengolahan sampah yang banyak membuang material ke lingkungan dan menghasilkan banyak emisi.

2. Pembebanan lingkungan terbesar kedua adalah pada tahap pengangkutan sampah.

3. Dampak lingkungan terbesar yang ditimbulkan oleh daur hidup sistem tercampur adalah gangguan keseimbangan ekologi.

4. Penggunaan energi terbesar pada sistem tercampur ini adalah pada tahap pengangkutan sampah.

\section{Interpretasi Daur Hidup Sistem Pengelolaan Sampah Sistem Terpisah}

Tabel pembobotan lingkungan menunjukkan bahwa:

1. Pembebanan lingkungan utama adalah tahap pengolahan sampah.

2. Tahap pengangkutan pada PSSP memberikan pembebanan lingkungan terbesar kedua setelah tahap pengolahan sampah.

3. Dampak lingkungan yang ditimbulkan oleh pengelolaan sampah institusi PSSP mulai dari yang terbesar sampai yang terkecil secara berurutan adalah adalah gangguan keseimbangan ekologi, gangguan kesehatan manusia, dan penyusutan sumber daya alam.

4. Konsumsi energi terbesar adalah pada tahap pengangkutan sampah.

\section{Perbandingan Daur Hidup PSSC dan PSSP}

Jika dilihat perbandingan pembebanan lingkungan yang ditimbulkan antara PSSC dan PSSP pada kuantitas yang sama, yaitu $5,1143 \mathrm{~m}^{3}$ sampah, PSSC akan menghasilkan beban lingkungan yang lebih besar bila dibandingkan dengan PSSP. Oleh karena itu dapat disimpulkan bahwa PSSP lebih ramah lingkungan dibandingkan PSSC.

\section{Usulan Perbaikan Sistem}

Adapun usulan untuk perbaikan sistem yaitu:

1. Mengoptimalkan pemilahan dan pemanfaatan sampah

2. Menggunakan jalur transportasi yang efektif

3. Penggunaan bahan bakar ramah lingkungan

4. Penggunaan sarana transportasi pengangkutan sampah sedikit emisi.

5. Membuang sampah yang dihasilkan lapak dan bandar ke TPA

6. Memperpendek jalur distribusi sampah daur ulang

\section{SIMPULAN}

Tahapan daur hidup PSSC dan PSSP yang memberikan dampak lingkungan hanya pada tahap pengolahan dan pengangkutan sampah.

Dampak lingkungan terbesar yang terjadi pada PSSC berupa potensi gangguan keseimbangan ekologi.

Pada PSSP, dampak lingkungan terbesar yang ditimbulkan sampai yang terkecil adalah gangguan keseimbangan ekologi, gangguan kesehatan manusia, dan penyusutan sumber daya alam.

Pembebanan lingkungan terbesar pada PSSC dan PSSP berasal dari pembuangan sampah kertas, plastik, penggunaan bahan bakar, serta sampah makanan dan halaman ke lingkungan.

Penggunan energi terbesar pada kedua sistem pengelolaan sampah terdapat pada tahap pengangkutan.

\section{DAFTAR PUSTAKA}

Aziz, R. 2005. Life Cycle Design pada Produk Air Minum Dalam Kemasan (Studi Kasus PT. AMIA). Teknik Lingkungan, Institut Teknologi Bandung: Bandung.

Badan Pusat Statistik, 2006. Padang Dalam Angka 2006: Padang. 
Fava J.A, F. Consoli, R. Denison, K. Dickson, T. Mohin, and B. Vigon (eds). A Conceptual Framework for Life-Cycle Impact Assessment. Society of Environmental Toxicology and Chemistry, February 1-7, 1992, Sandestin, Fla., 1993, pp.4-8, 11, 19: Pensacola.

Freeman, M. Harry. (1995). Industrial Prevention Handbook. Mc Graw-Hill Companies. Inc.USA.

G.H Tchnobanoglous, H. Thiessen, S.A Vigil. 1993. Integrated of Solid Waste Management. Mc Graw Hill Inc: New York.

Graedel, T.E., Allenby, B. R. 1995. Industrial Ecology. New Jersey: Prentience Hall.

Hafshoh, D. 2008. Pengelolaan Sampah Plastik Dari Sumber Institusi di Kota Padang. Teknik Lingkungan, Universitas Andalas: Padang.

ISO 14040: Environmental management Life cycle assessment - Principles and framework. International Standard ISO 14040.

Jensen, A.,Leif H., Birgitte T. Moller, Anders Schmidt. Life Cycle Assessment (LCA): A guide to approach, experiences, and information sources. European Environment Agency: Europe.
Kirkeby, Janus T. 2005. Environmental Assessment of Solid Waste System and Technologies: EASEWASTE. Environment and Resources, Technical University of Denmark: Denmark.

Nitri, S. 2008. Pengelolaan Sampah Kertas Dari Sumber Institusi di Kota Padang. Jurusan Teknik Lingkungan, Universitas Andalas: Padang.

Pemerintah Kota Padang, 2006. Kondisi Eksisting Program Adipura 2006-2007. Padang.

Surjowidjojo, W. 1999. Inventory Analysis dalam Life Cycle Assessment Product. Pelatihan Life Cycle Analysis Product: Bandung.

Surjowidjojo, W. 1999. Konsep dan Pendekatan Produk LCA. Pelatihan Life Cycle Analysis Product: Bandung.

Thorneloe, S. 2007. Holistic Evaluation of Life Cycle Environment Tradeoffs for Municipal Solid Waste and Materials Management. Environmental Protection Agency: United States.

Wibowo, A. 1999. Product Life Cycle Analysis Dalam Kebijaksanaan Pengelolaan Lingkungan di Indonesia. Pelatihan Life Cycle Analysis Product: Bandung.

Wirawat C, Shabbir H. Gheewala. 2006. Life Cycle Assessment of MSW to Energy Schemes in Thailand. King Mongkut's Institute of Technology Ladkrabang, Chumphon: Thailand. 